\title{
EDITORIAL
}

\section{Confounded by time}

One of the first elements of the scientific management courses on which the AFRC used to send its budding project leaders was the management of one's own working (and, by inference, free) time. The emphasis was, as I recall, working out what had to be done, assigning priorities and making sure that the time allocated to each task was sufficient to make some progress. One came back from such a course determined to practise what one had learned because it seemed that it would make life so much easier. In real life it was, however, very difficult, principally because only the very fortunate or extraordinarily cussed individuals are not affected by the time schedules imposed by others. I often felt that time-management courses were the one aspect of scientific research that should be organized in a 'top-down' fashion and that the concepts embodied in the principles of time management seemed quite foreign to the way things are. Of course we have all met those who think that authority depends on fear and who use deadlines as one method for establishing their authority. While there are others whose own time management is governed by chaos theory and who therefore set deadlines which are entirely unrealistic, simply to allow themselves some breathing-space to get things done.

I have written before of the way in which deadlines dominate the whole life of those concerned with publishing; I am quite sure that the concept of 'just-in-time production' beloved by Japanese car manufacturers was actually invented by journalists writing their copy with quills pens. At the Editorial Office, meeting the deadline for providing the Press with copy is of course the first step in a highly organized production process whose efficiency has been developed by one of the most potent forces, the control of costs.

Our problem is interfacing between the pressures of the printing world and that of scientific research. This means that if we are to meet deadlines and our objectives of publishing closely peer-reviewed research papers and reducing the times between submission, acceptance, and publication, we have to look very carefully at the way we operate against the old enemy, time.

Scientific journals such as the British Journal of Nutrition have grown, like the science which they serve, relying on the services of the committed 'amateur' scientist, using 'amateur' in the literal sense of being committed out of over-riding interest in the science. I recognize that the day of the amateur carrying out scientific research from his or her own resources disappeared a long time ago, although not as long as you might think. My first boss in Cambridge had a spectrophotometer he had purchased himself because he needed it. I might also add that many of my European colleagues look with disdain on a researcher who is not prepared to fund his or her own travel to a key meeting, and I suspect several of my academic colleagues know that they cannot rely on funding for travel to all the meetings which scientifically would benefit them.

However, the point which I wish to make is that the operation of the Journal depends on members of the Editorial Board and referees carrying out the detailed reviewing process as their contribution to the progress of Nutritional Science. One could argue that this is quite right and proper because the experience gained in refereeing and serving on an Editorial Board improves one's own skills in writing and constructing papers in a way that is difficult to achieve by any other route. 
Refereeing and editorial reviewing is, however, a time-consuming process demanding dedication and attention to detail. It is increasingly evident from my own experience that the pressures on the time of all researchers are becoming greater all the time. The time allocated to projects is being strictly monitored externally and in all cases the penalties for not conforming to these external constraints can be very severe. First the funding starts to dry-up, then names start to move up the list of those who are not publishing at the perceived desirable rates and then....

I see these issues as very critical for the success of all journals. There is a real need to respond to this increasing professionalism, which in itself has some positive benefits. In the Editorial Office we are seeking to bring in-house as much as we can of the work load. Electronic mail, for example, could relieve the trivial but tiresome delays in the post. The strength of the scientific backgrounds in the Editorial Office means that decisions can be taken without always going back to the Editor. However, it is clear that the Editorial Board systems which we have relied on in the past need radical revision to reduce the pressures on the members of the Editorial Board. We can, and indeed will have to, increase the membership of the Board and we will have to recognize that our targets for the 'times to first decision', which I think is important to authors, will have to conform with the facts of life about the ways in which researchers are expected to manage their time.

D. A. T. Southgate 